\title{
Seismic Behavior Research and Strengthening Measures of Bottom Frame--anti-seismic Wall Masonry Structure
}

\author{
Su Gao \\ College of Construction Engineering, Nantong Vocational University, Nantong, China \\ Email address: \\ 233447216@qq.com \\ To cite this article: \\ $\mathrm{Su}$ Gao. Seismic Behavior Research and Strengthening Measures of Bottom Frame--anti-seismic Wall Masonry Structure. Engineering and \\ Applied Sciences. Vol. 5, No. 6, 2020, pp. 98-105. doi: 10.11648/j.eas.20200506.11
}

Received: November 15, 2019; Accepted: January 10, 2020; Published: November 11, 2020

\begin{abstract}
In this paper, the mechanical characteristics and seismic performance of the bottom frame anti-seismic wall structure are analyzed. According to the calculation formula given in the code, the calculation and analysis of the four story store house with the bottom one story frame are carried out. Under the minimum material strength specified in the code, the floor stiffness ratio, equivalent stiffness, wall and frame seismic action of the bottom story are calculated. At the same time, the type, the material strength and the restrained anti-seismic wall are calculated. The results show that the number of the seismic walls has a great influence on the effective stiffness of the bottom floor, the stiffness ratio between floors, the seismic action of the wall and the seismic action of the frame column, and the key influencing factors are determined. The conclusions are as follows: by increasing the concrete strength of the seismic wall at the bottom, the stiffness of the bottom floor is increased; the strength of the block is increased, and the seismic shear allocated to the column is reduced; the number of the seismic wall has a great influence on the seismic action of the frame column at the bottom. The influence of the stiffness ratio between layers is small; the use of reinforced concrete seismic wall can optimize the stiffness ratio between layers, reduce the number of the wall, and provide a reference for the selection of engineering reinforcement scheme.
\end{abstract}

Keywords: Bottom Frame-seismic Wall Masonry Building, Seismic Performance, Storey Stiffness Ratio, Seismic Action, Influence Factors

\section{Introduction}

The bottom frame--anti-seismic wall structure has the characteristics of "upper rigid-lower flexible" and "head heavy-foot light", which is an unfavorable structure form for anti-seismic.

From the statistical analysis of earthquake damage [1-5], it is found that among all kinds of earthquake damage, the collapse of the bottom frame is the most serious. But limited to the current economic development level of our country, as well as the characteristics of the bottom frame anti-seismic wall house that can meet the needs of the large space at the bottom, convenient and flexible use, and relatively low construction cost, the demolition and resettlement house building with shops in the street commercial residence, office building, as well as some public buildings that need large space at the bottom, such as shops, hotels, post offices, hotels, banks, etc construction continues in China. Therefore, this paper studies the seismic performance of this kind of structure, analyzes the influencing factors of the seismic performance of the bottom frame, prevents the continuous collapse and damage during the earthquake, provides a reference for the design methods and measures to improve the seismic capacity of new structures, and provides a theoretical basis for the seismic reinforcement methods of the bottom frame seismic wall structure built before the implementation of the code for seismic design of buildings (GB50011-2010).

\section{The Influence of the Stiffness Ratio on Bottom Frame of Seismic Performance}

The bottom frame anti-seismic wall building is a building with mixed load-bearing of two different materials. The anti-seismic performance of the two materials is different (especially the difference in elastic modulus). The bottom frame anti-seismic wall is a rigid flexible structure, which mainly bears the vertical load by the frame, the anti-seismic wall bears the horizontal earthquake action, and the upper 
masonry structure is a rigid structure, which depends on the masonry wall to resist shear [6, 7].

The horizontal seismic shear force of the upper masonry structure depends on the the transition floor slab transfered to the lower seismic wall, which belongs to the irregular structure with large lateral stiffness change and indirect force transfer, and the system is extremely unreasonable [8]. According to the seismic damage survey, the bottom of the building is an obvious weak part, which is prone to stress concentration and deformation concentration. The elastic interlayer displacement response is relatively uniform during small earthquakes. Under the action of large earthquakes, the elastic-plastic deformation concentration at the bottom will yield first, cause large lateral displacement, damage or collapse, and its seismic performance is worse than that of multi-storey masonry buildings of the same height. According to the elastic design under "small earthquake" in the first stage, the weak layer can also meet the requirements of seismic bearing capacity checking, so it is difficult to find problems and ensure the safety of the house under "large earthquake" [9-10]. This paper studies the influence of the factors such as the stiffness ratio between floors, the number of anti-seismic walls and the types of anti-seismic walls on the seismic action of the bottom frame, so as to ensure the anti-seismic target of the bottom frame that "large earthquake does not collapse".

\section{The Influence of the Stiffness Ratio on Wall Structure of Seismic Performance}

\subsection{Calculation of Storey Stiffness Ratio}

Storey stiffness ratio refers to the ratio of the lateral stiffness of the bottom or bottom two layers of the structure to the adjacent upper layers. For the anti-seismic wall masonry structure with frame only on the bottom floor, the lateral stiffness ratio $r$ value of the second floor to the bottom floor is calculated according to the following formula in both vertical and horizontal directions [11]:

$$
\begin{aligned}
& r=\frac{\Sigma K_{b 2 j}}{\Sigma K_{c f j}+\Sigma K_{b 1 j}} \\
& r=\frac{\Sigma K_{b 2 j}}{\Sigma K_{c f j}+\Sigma K_{c w j}+\Sigma K_{g w j}}
\end{aligned}
$$

In the formula $\Sigma K_{b 2 j}, \Sigma K_{b 1 j}, \Sigma K_{c f j}, \Sigma K_{c w j}$, $\Sigma K_{g W j}$ respectively, are the storey lateral stiffness of the two-story one-piece restrained masonry seismic wall, the bottom one-piece restrained masonry seismic wall, the bottom one reinforced concrete frame, the bottom one reinforced concrete seismic wall, and the bottom one reinforced small block masonry seismic wall.

Lateral stiffness of the frame:

$$
K_{c j j}=\Sigma K_{c j}=\Sigma \frac{12 E_{\mathrm{c}} I_{c}}{H_{1}^{3}}
$$

Lateral stiffness of reinforced concrete wall:

$$
\begin{aligned}
& K_{c w j}=\frac{1}{\frac{1.2 h}{G_{C} A}+\frac{h^{3}}{6 G_{C} I}} \\
& K_{g w j}=\frac{1}{\frac{1.2 h}{G_{g} A}+\frac{h^{3}}{6 G_{g} I}}
\end{aligned}
$$

Lateral stiffness of reinforced small block masonry seismic wall:

There are two cases for the lateral stiffness of the restrained brick masonry seismic wall. For low seismic wall, when the ratio of height to width is less than 1 , only shear deformation is considered, otherwise shear deformation and bending deformation are considered simultaneously.

Shear deformation only (rectangular section):

$$
K_{\mathrm{b} j}=\frac{G A}{1.2 h}
$$

Both shear and bending deformation:

$$
K_{b j}=\frac{1}{\frac{1.2 h}{G A}+\frac{h^{3}}{12 E I}}
$$

\subsection{Calculation of Effective Lateral Stiffness and Seismic Action of Bottom Frame}

Before the seismic wall cracks during the earthquake, because the lateral stiffness of the seismic wall is much larger than that of the frame, the storey seismic shear assigned by the seismic wall in the same direction often accounts for more than $90 \%$ of the total storey seismic shear [12], therefore, the code takes the seismic wall as the first line of defense, requiring to bear all the seismic shear force, excluding the frame effect, and takes the frame as the second line of defense.

When the anti-seismic wall cracks, its lateral stiffness decreases to about $30 \%$ of the initial elastic stiffness [12], and then with the increase of deformation, the stiffness of frame and anti-seismic wall decreases. Therefore, according to the code, the seismic shear force bearing by the bottom frame is distributed according to the effective lateral stiffness, and the calculation formula of the horizontal seismic shear force bearing by the bottom frame column is as follows:

$$
\begin{aligned}
& V_{C}=\frac{K_{c}}{\Sigma K_{c j j}+0.3 \Sigma K_{c w j}+0.2 \Sigma K_{b 1 j}} \cdot V_{1} \\
& V_{C}=\frac{K_{c}}{\Sigma K_{c j j}+0.3 \Sigma K_{g w j}+0.2 \Sigma K_{b 1 j}} \cdot V_{1}
\end{aligned}
$$

\subsection{The Influence of the Storey Stiffness Ratio on the Seismic Action of the Bottom Frame}

It is found that [13], the ratio of the lateral stiffness of the 
bottom floor or the bottom two floors of the bottom frame anti-seismic wall structure to the adjacent upper floors is in a reasonable range, neither too weak nor too strong. Too weak is not good for the bottom structure itself, and too strong may cause the bottom to absorb too much seismic action, and at the same time cause the transfer of the weak part of the structure, that is, the weak part is transferred from the reinforced concrete structure with good ductility at the lower part to the masonry structure with poor ductility at the upper part, which is not good for the earthquake resistance of the structure.

In order to achieve the goal of seismic fortification, the seismic code puts forward specific requirements for the range of stiffness ratio between floors. At the same time, the test results show that [13]: when the lateral stiffness ratio of the second floor to the bottom floor is about 1.5, the upper masonry building is under uniform stress, and the overall seismic performance of the structure is normal; When the lateral stiffness ratio between the second floor and the bottom floor is $\mathrm{k}<1.2$, especially $\mathrm{k}<1.0$, the weak floor is no longer the bottom floor, but transferred to the part of the upper masonry building with small storey shear force, which is unfavorable for earthquake resistance; In order to ensure the anti-seismic effect, the stiffness ratio between layers should be controlled at $1.2 \sim 2.0$, and the limit value of reinforced concrete wall can be appropriately relaxed, but should not be greater than 2.5 .

\section{Influence of Seismic Wall Type on Seismic Action of Bottom Frame}

\subsection{Project Overview}

A four story store house is a bottom frame anti-seismic wall structure with just one storey frame at the bottom. The seismic fortification intensity is calculated as 6,7 and 8 degrees respectively, and the site is classified as class II.

The longitudinal column spacing of the bottom frame of the house is $5.1 \mathrm{~m}$, and the transverse column spacing is $3.3 \mathrm{~m}$ and $2.7 \mathrm{~m}$. The floor height of the first floor is $4.5 \mathrm{~m}$, the floor height of the second to fourth floors is $2.8 \mathrm{~m}$, and it is a cast-in-place reinforced concrete building roof structure. The ground floor plan size is shown in Figure 1, the column section size is $400 \mathrm{~mm} \times 500 \mathrm{~mm}$, the frame beam section size is $300 \mathrm{~mm} \times 700 \mathrm{~mm}$, and the seismic wall section size is shown in Figure 2.

According to the structural requirements of code for seismic design of buildings [14], the construction materials are selected for the project.

Strength grade of the engineering materials: the bottom frame and anti-seismic wall materials are shown in Table 1, and when the anti-seismic intensity is 6 degrees and the total number of floors is not more than four, ordinary brick masonry or small block masonry anti-seismic wall is allowed to be used; in other cases, reinforced concrete anti-seismic wall shall be used when it is 8 degrees, and reinforced concrete anti-seismic wall or small block masonry anti-seismic wall with reinforcement shall be used when it is 6 or 7 degrees [14].

In the structure with two or more floors: mul0 sintered ordinary brick and M7.5 mixed mortar are used for brick masonry, the wall thickness is $240 \mathrm{~mm}$, which meets the structural requirements of restrained masonry; $\mathrm{C} 30$ concrete is used for structural column, ring beam and cast-in-place slab; the total lateral stiffness of seismic wall with two floors of restrained brick masonry is $1.592 \times 10^{7} \mathrm{KN} / \mathrm{m}$. The four corners of the house, the four corners of the stairwell, the junction of the outer wall and the vertical and horizontal wall axes, and the two sides of the large opening are provided with structural columns, and all the walls are provided with ring beams.

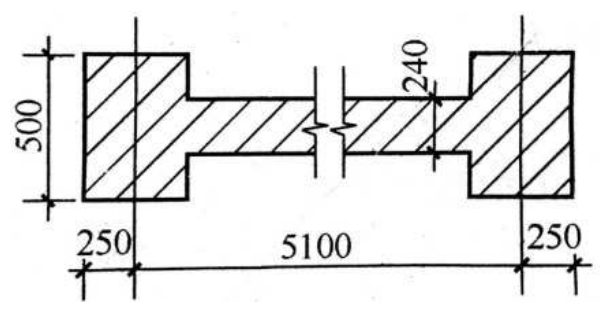

Figure 1. Ground floor plan.

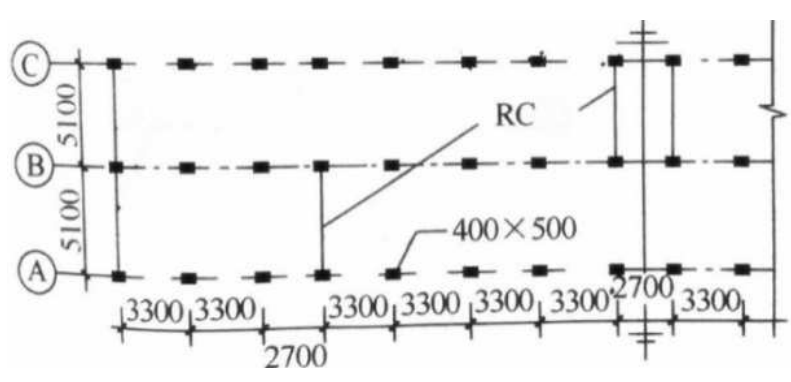

Figure 2. Section of seismic wall.

\subsection{Physical Parameters of Bottom Structure}

According to the code for seismic design [14], the strength grade of mortar shall not be lower than M10 for restrained brick masonry seismic wall, and not be lower than Mb10 for restrained small block masonry wall. Therefore, select the materials that meet the requirements, and list the elastic modulus and other physical parameters of masonry materials in Table 1 according to the code for design of masonry structures [15].

Table 1. Physical parameters of bottom structure material.

\begin{tabular}{|c|c|c|c|c|c|}
\hline \multicolumn{2}{|c|}{ Material type } & Elastic modulus $\left(\mathrm{N} / \mathrm{m}^{2}\right)$ & Shear modulus $\left(\mathrm{N} / \mathrm{m}^{2}\right)$ & Linear expansion coefficient $\left(10^{-6} / \mathrm{C}\right)$ & Poisson's ratio \\
\hline \multirow{4}{*}{$\begin{array}{l}\text { Brick } \\
\text { masonry }\end{array}$} & MU20 M15 & $5.15 \mathrm{e}^{9}$ & $2.06 \mathrm{e}^{9}$ & 5 & 0.15 \\
\hline & MU20 M10 & $4.27 \mathrm{e}^{9}$ & $1.71 \mathrm{e}^{9}$ & 5 & 0.15 \\
\hline & MU15 M15 & $4.464 \mathrm{e}^{9}$ & $1.78 \mathrm{e}^{9}$ & 5 & 0.15 \\
\hline & MU10 M10 & $3.02 \mathrm{e}^{9}$ & $1.21 \mathrm{e}^{9}$ & 5 & 0.15 \\
\hline
\end{tabular}




\begin{tabular}{llllll}
\hline Material type & Elastic modulus $\left(\mathbf{N} / \mathbf{m}^{2}\right)$ & Shear modulus $\left(\mathbf{N} / \mathbf{m}^{2}\right)$ & Linear expansion coefficient $\left(\mathbf{1 0} \mathbf{0}^{-6} / \mathbf{C}\right)$ & Poisson's ratio \\
\hline \multirow{6}{*}{ Block } & MU20 Mb20 & $10.71 \mathrm{e}^{9}$ & $4.28 \mathrm{e}^{9}$ & 10 & 0.15 \\
masonry & MU20 Mb15 & $9.66 \mathrm{e}^{9}$ & $3.86 \mathrm{e}^{9}$ & 10 & 0.15 \\
& MU20 Mb10 & $8.42 \mathrm{e}^{9}$ & $3.37 \mathrm{e}^{9}$ & 10 & 0.15 \\
& MU15 Mb15 & $7.84 \mathrm{e}^{9}$ & $3.14 \mathrm{e}^{9}$ & 10 & 0.15 \\
& MU15 Mb10 & $6.83 \mathrm{e}^{9}$ & $2.73 \mathrm{e}^{9}$ & 10 & 0.15 \\
& MU10 Mb10 & $4.74 \mathrm{e}^{9}$ & $1.90 \mathrm{e}^{9}$ & 0.15 \\
& C50 & $3.45 \mathrm{e}^{10}$ & $1.38 \mathrm{e}^{10}$ & 10 & 0.2 \\
Concrete & C45 & $3.35 \mathrm{e}^{10}$ & $1.34 \mathrm{e}^{10}$ & 10 & 0.2 \\
& C40 & $3.25 \mathrm{e}^{10}$ & $1.30 \mathrm{e}^{10}$ & 10 & 0.2 \\
& C35 & $3.15 \mathrm{e}^{10}$ & $1.26 \mathrm{e}^{10}$ & 10 & 0.2 \\
& C30 & $3.00 \mathrm{e}^{10}$ & $1.20 \mathrm{e}^{10}$ & 10 & 0.2 \\
\hline
\end{tabular}

\subsection{Analysis of the Influence of the Type of Anti-seismic Wall on the Stiffness and Anti-seismic Bearing Capacity of the Bottom Storey}

When the concrete strength grade of frame beam, column and anti-seismic wall is $\mathrm{C} 30$ and MU10 sintered ordinary brick and M10 mixed mortar are used for brick masonry, the calculation is as follows:

1) Total lateral stiffness of bottom layer $\mathrm{K} 1$

The lateral stiffness of the 5 column is calculated by formula (2):

$$
K_{c f}=40 \times \frac{12 \times 3 \times 10^{4} \times \frac{1}{12} \times 400 \times 500^{3}}{4500^{3}}=1.646 \times 10^{4} \mathrm{kN} / \mathrm{m}
$$

The lateral stiffness of a concrete anti-seismic wall is calculated by formula (3):

$$
\begin{gathered}
A=0.24 \times 5.6+2 \times 0.5 \times(0.5-0.24)=1.604 \mathrm{~m}^{2} \\
I=\frac{1}{12} \times 0.5 \times 5.6^{3}-\frac{1}{12} \times(0.5-0.24) \times 5.1^{3}=4.443 \mathrm{~m}^{4} \\
K_{c w}=\frac{1}{\frac{1.2 \times 4.5}{0.4 \times 3 \times 10^{4} \times 10^{3} \times 1.604}+\frac{4.5^{3}}{6 \times 3 \times 10^{4} \times 10^{3} \times 4.443}} \\
=2.535 \times 10^{6} \mathrm{kN} / \mathrm{m}
\end{gathered}
$$

The lateral stiffness of a confined brick masonry anti-seismic wall of a low-rise wall is calculated by formula (5):

When two reinforced concrete anti-seismic walls and two brick masonry anti-seismic walls are used in the project, the total lateral stiffness of the bottom layer is:

$$
\begin{aligned}
& K_{1}=\Sigma K_{c}+\Sigma K_{c \mathrm{w}}+\Sigma K_{b}=(0.658+4 \times 2.535+4 \times 0.293) \times 10^{6} \\
& =11.968 \times 10^{6}
\end{aligned}
$$

Lateral stiffness ratio:

$$
r=\frac{K_{2}}{K_{1}}=\frac{1.592 \times 10^{7}}{11.968 \times 10^{6}}=1.33
$$

Shear adjustment coefficient of the bottom layer:

$$
\mu=1.2+\frac{1.33-1}{2.5-1} \times(1.5-1.2)=1.28
$$

Bottom shear force:

$$
V_{1}=1.28 V_{0}
$$

Seismic shear force bearing by a brick masonry seismic wall:

$$
\begin{aligned}
& V_{c w}=\frac{K_{b}}{\Sigma K_{c w}+\Sigma K_{b}} \cdot V_{1}=\frac{2.93 \times 10^{5}}{10.14 \times 10^{6}+1.17 \times 10^{6}} \times 1.28 V_{0} \\
& =0.033 V_{0}
\end{aligned}
$$

A piece of reinforced concrete seismic wall bearing the

\begin{tabular}{|c|c|c|c|c|c|}
\hline Wall types & & $\begin{array}{l}\text { One piece wall lateral } \\
\text { stiffness }(\mathrm{KN} / \mathrm{m})\end{array}$ & $\begin{array}{l}\text { lateral stiffness } K_{1} \\
(\mathrm{KN} / \mathrm{m})\end{array}$ & stiffness ratio $r=\frac{K_{2}}{K_{1}}$ & $\begin{array}{l}\begin{array}{l}\text { Equivalent lateral } \\
\text { stiffness } K_{0}(\mathrm{KN} / \mathrm{m})\end{array} \\
\end{array}$ \\
\hline \multirow{4}{*}{$\begin{array}{l}\text { Restrained brick masonry } \\
\text { seismic wall }\end{array}$} & MU20 M15 & 4.99 e 5 & $12.79 \mathrm{e} 6$ & 1.24 & $4.10 \mathrm{e} 6$ \\
\hline & MU20 M10 & 4.14 e 5 & $12.45 \mathrm{e} 6$ & 1.28 & $4.03 \mathrm{e} 6$ \\
\hline & MU15 M15 & $4.32 \mathrm{e} 5$ & $12.53 \mathrm{e} 6$ & 1.27 & 4.06 e 6 \\
\hline & MU15 M10 & $3.58 \mathrm{e} 5$ & $12.23 \mathrm{e} 6$ & 1.30 & $3.99 \mathrm{e} 6$ \\
\hline
\end{tabular}
shear force:

$$
\begin{aligned}
& V_{c w}=\frac{K_{c w}}{\Sigma K_{c w}+\Sigma K_{b}} \cdot V_{1}=\frac{2.353 \times 10^{5}}{10.14 \times 10^{6}+1.17 \times 10^{6}} \times 1.28 V_{0} \\
& =0.29 V_{0}
\end{aligned}
$$

Design value of a frame column bearing seismic shear force:

$$
\begin{aligned}
& V_{C}=\frac{K_{c}}{\Sigma K_{c f}+0.3 \Sigma K_{c w}+0.2 \Sigma K_{b 1}} \cdot V_{1} \\
& =\frac{}{0.658 \times 10^{6}+0.3 \times 10.14 \times 10^{6}+0.2 \times 1.17 \times 10^{6}} \\
& =0.0054 V_{0}
\end{aligned}
$$

When the material strength of restrained brick masonry seismic wall, reinforced block masonry and reinforced concrete seismic wall is changed respectively, and other conditions are unchanged, according to the above formula, the calculated results are shown in Table 2.

Table 2. The bottom frame-aseismic wall layer between the lateral stiffness ratio and earthquake action. 


\begin{tabular}{|c|c|c|c|c|c|}
\hline Wall types & & $\begin{array}{l}\text { One piece wall lateral } \\
\text { stiffness }(\mathrm{KN} / \mathrm{m})\end{array}$ & $\begin{array}{l}\text { lateral stiffness } K_{1} \\
(\mathrm{KN} / \mathrm{m})\end{array}$ & stiffness ratio $r=\frac{K_{2}}{K_{1}}$ & $\begin{array}{l}\text { Equivalent lateral } \\
\text { stiffnessK }_{0}(K N / m)\end{array}$ \\
\hline \multirow{6}{*}{$\begin{array}{l}\text { Restrained block masonry } \\
\text { seismic wall }\end{array}$} & MU10 M10 & 2.93 e 5 & $11.97 \mathrm{e} 6$ & 1.33 & $3.93 \mathrm{e} 6$ \\
\hline & MU20 Mb20 & 4.15 e 5 & $12.46 \mathrm{e} 6$ & 1.28 & $4.03 \mathrm{e} 6$ \\
\hline & MU20 Mb10 & $3.27 \mathrm{e} 5$ & $12.10 \mathrm{e} 6$ & 1.32 & $3.96 \mathrm{e} 6$ \\
\hline & MU15 Mb15 & $3.04 \mathrm{e} 5$ & $12.01 \mathrm{e} 6$ & 1.33 & 3.94 e 6 \\
\hline & MU15 Mb10 & $2.65 \mathrm{e} 5$ & $11.86 \mathrm{e} 6$ & 1.34 & $3.91 \mathrm{e} 6$ \\
\hline & MU10 Mb10 & $1.84 \mathrm{e} 5$ & $11.53 \mathrm{e} 6$ & 1.38 & 3.84 e 6 \\
\hline \multirow{5}{*}{$\begin{array}{l}\text { Restrained concrete } \\
\text { seismic wall }\end{array}$} & $\mathrm{C} 50$ & $2.92 \mathrm{e} 6$ & $13.59 \mathrm{e} 6$ & 1.17 & 4.49 e 6 \\
\hline & $\mathrm{C} 45$ & 2.83 e 6 & $13.23 \mathrm{e} 6$ & 1.20 & $4.36 \mathrm{e} 6$ \\
\hline & $\mathrm{C} 40$ & $2.75 \mathrm{e} 6$ & 12.87 e 6 & 1.24 & 4.24 e 6 \\
\hline & $\mathrm{C} 35$ & 2.66 e 6 & $12.51 \mathrm{e} 6$ & 1.27 & $4.12 \mathrm{e} 6$ \\
\hline & $\mathrm{C} 30$ & $2.53 \mathrm{e} 6$ & $11.97 \mathrm{e} 6$ & 1.33 & $3.93 \mathrm{e} 6$ \\
\hline
\end{tabular}

Table 2. Continued.

\begin{tabular}{|c|c|c|c|c|c|}
\hline Wall types & & $\begin{array}{l}\text { seismic shear adjustment } \\
\text { coefficient of the bottom floor }\end{array}$ & $\begin{array}{l}\text { seismic shear coefficient of } \\
\text { one brick masonry wall }\end{array}$ & $\begin{array}{l}\text { seismic shear coefficient of } \\
\text { one reinforced concrete wall }\end{array}$ & $\begin{array}{l}\text { seismic shear coefficient } \\
\text { of one column }\end{array}$ \\
\hline \multirow{5}{*}{$\begin{array}{l}\text { Restrained } \\
\text { brick masonry } \\
\text { seismic wall }\end{array}$} & MU20 M15 & 1.25 & 0.051 & 0.261 & 0.005380 \\
\hline & MU20 M10 & 1.26 & 0.044 & 0.266 & 0.005594 \\
\hline & MU15 M15 & 1.25 & 0.040 & 0.267 & 0.005533 \\
\hline & MU15 M10 & 1.26 & 0.039 & 0.274 & 0.005697 \\
\hline & MU10 M10 & 1.27 & 0.033 & 0.280 & 0.005857 \\
\hline \multirow{5}{*}{$\begin{array}{l}\text { Restrained } \\
\text { block masonry } \\
\text { seismic wall }\end{array}$} & MU20 Mb20 & 1.256 & 0.044 & 0.270 & 0.004923 \\
\hline & MU20 Mb10 & 1.263 & 0.036 & 0.280 & 0.005080 \\
\hline & MU15 Mb15 & 1.265 & 0.034 & 0.282 & 0.005122 \\
\hline & MU15 Mb10 & 1.269 & 0.030 & 0.287 & 0.005197 \\
\hline & MU10 Mb10 & 1.276 & 0.022 & 0.297 & 0.005356 \\
\hline \multirow{4}{*}{$\begin{array}{l}\text { Restrained } \\
\text { concrete } \\
\text { seismic wall }\end{array}$} & $\mathrm{C} 50$ & 1.23 & 0.028 & 0.2272 & 0.005180 \\
\hline & $\mathrm{C} 45$ & 1.24 & 0.029 & 0.2266 & 0.005199 \\
\hline & $\mathrm{C} 40$ & 1.25 & 0.030 & 0.2260 & 0.005219 \\
\hline & $\mathrm{C} 30$ & 1.27 & 0.033 & 0.2241 & 0.005272 \\
\hline
\end{tabular}

When the structural arrangement of seismic wall at the bottom is not changed, only the wall material is changed, it can be seen from the calculation in Table 2:

1) When the strength of confined brick masonry or block masonry material is only increased, the rigidity of brick masonry seismic wall, the lateral rigidity of bottom floor, the equivalent lateral rigidity and the seismic shear force of brick masonry wall increase with the increase of material strength, while the storey rigidity ratio, the adjustment coefficient of seismic shear force of bottom floor, the seismic shear force of reinforced concrete seismic wall and column decrease with the increase of brick masonry material strength, The storey stiffness ratio is within the range of the code.

Among them, for brick masonry confined wall, when the mortar strength is constant and the strength of block is increased by one level, the lateral stiffness of the bottom floor increases by about $2 \%$; the equivalent lateral stiffness increases by about $1 \%$; the seismic shear of the bottom column decreases by $1.8 \%$ $\sim 2.7 \%$; the seismic shear of the bottom concrete anti-seismic wall decreases by $2.1 \% \sim 2.9 \%$; the seismic shear of a brick masonry wall increases by $12.8 \% \sim 27.5 \%$.

For the single row of block masonry confined wall, When the strength of block and mortar is increased by one grade, the lateral stiffness of the bottom floor increases by about $2 \%$; the equivalent lateral stiffness increases by about $1.5 \%$; the seismic shear value for each component of the bottom floor: one block masonry wall increases by $36 \% \sim 10 \%$, the bottom column decreases by $0.8 \% \sim 2.97 \%$; the bottom concrete seismic wall decreases by $0.7 \% \sim 3.37 \%$, and the increase scope of the seismic effect decreases with the increase of material strength is reducing, that is to say, for the confined block masonry, the increase of material strength to a certain extent does not significantly improve the bottom seismic action.

2) If just the strength grade of the concrete anti-seismic wall in the project is increased, and the masonry material is unchanged and When the strength of concrete is increased by one grade, the seismic shear force bearing by each component will be increased by $2.7 \% \sim 4.5 \%$, the equivalent lateral stiffness will be increased by $3 \%$, the reinforced concrete anti-seismic wall will be increased by $0.5 \%$, the shear force bearing by the confined brick masonry wall and column will be reduced, and the column will be reduced by $0.4 \%$.

\subsection{Analysis About the Influence of the Number of Anti-seismic Walls on the Stiffness and Seismic Action of the Bottom Floor}

The concrete strength grade of frame beam, column and anti-seismic wall is C30, and MU10 sintered ordinary brick and M10 composite mortar are used for brick masonry. When only one type of anti-seismic wall is used in the project, the influence of different number of anti-seismic walls on storey stiffness ratio and column seismic shear coefficient is calculated, as shown in figure 3-figure 5. 


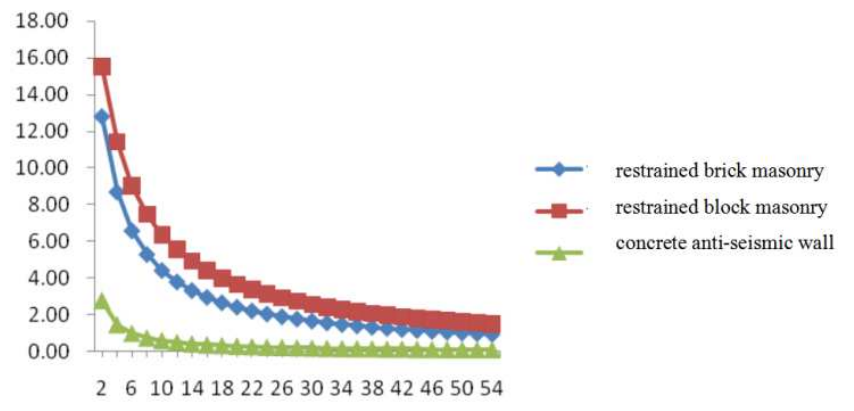

Figure 3. The influence of the number of the seismic wall on the stiffness ratio of the bottom frame-seismic wall.

It can be seen from Figure 3 that for the same number of anti-seismic walls, when all concrete anti-seismic walls are set, the storey stiffness ratio is the minimum; with the increase of the number of walls, the storey stiffness ratio shows a downward trend, and when the number of walls increases to a certain amount, the storey stiffness ratio tends to a stable value.

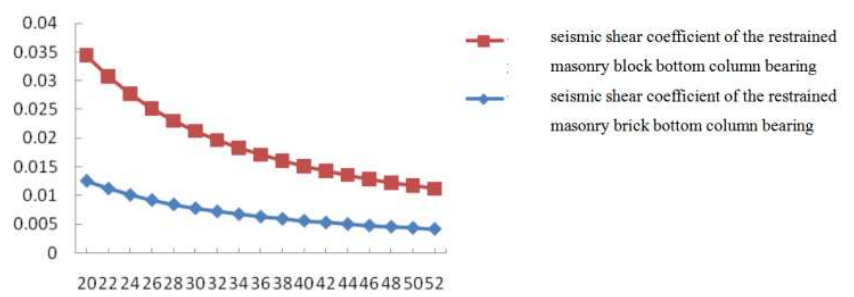

Figure 4. The effect of the number of constraint blocks and block masonry walls on the seismic effect of columns.

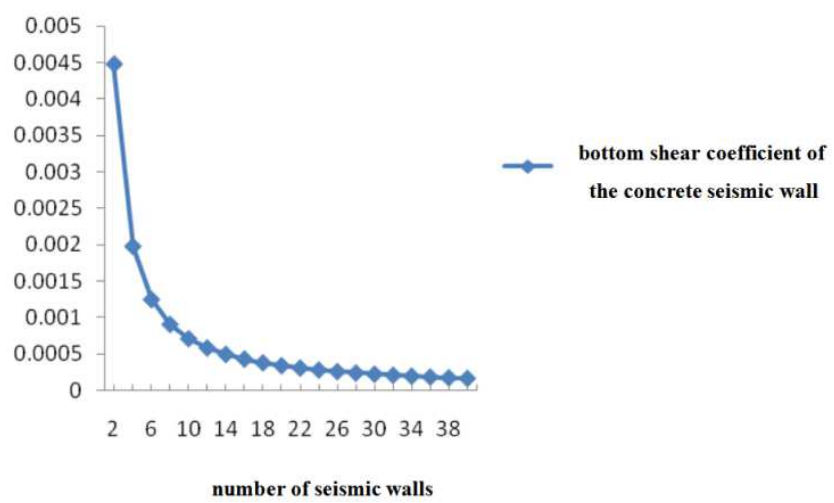

Figure 5. Effect of confined concrete wall on the seismic effect of columns.

It can be seen from Figure 4 and Figure 5 that the number of confined brick masonry walls has little influence on the seismic action of the bottom column; within the reasonable value range of the storey stiffness ratio, the seismic action of the bottom column decreases with the increase of the number of concrete seismic walls, with obvious influence; when the storey stiffness ratio is not within the reasonable range, the seismic action of the bottom column changes little with the increase of the number of concrete seismic walls.

When the floor stiffness ratio is within a reasonable range, the seismic effect of the column decreases by $5 \%-2 \%$ with each increase of the number of walls, and the decrease scope with the increase of the number of walls.

Partial calculation results of the influence of the number of walls on the lateral stiffness and seismic action are listed in Table 3.

Table 3. The effect of the quantity of the seismic wall on the bottom and the distribution of earthquake action.

\begin{tabular}{|c|c|c|c|c|c|}
\hline Wall types & & $\begin{array}{l}\text { Total stiffness of the seismic } \\
\text { wall }(\mathrm{KN} / \mathrm{m})\end{array}$ & $\begin{array}{l}\text { lateral stiffness } K_{1} \\
(\mathrm{KN} / \mathrm{m})\end{array}$ & stiffness ratior $=\frac{K_{2}}{K_{1}}$ & $\begin{array}{l}\text { Equivalent lateral } \\
\text { stiffness } K_{0}(\mathrm{KN} / \mathrm{m})\end{array}$ \\
\hline \multirow{4}{*}{$\begin{array}{l}\text { Restrained brick } \\
\text { masonry seismic } \\
\text { wall }\end{array}$} & 2 & $5.86 \mathrm{e} 5$ & $1.244 \mathrm{e} 6$ & 12.80 & $4.10 \mathrm{e} 6$ \\
\hline & 4 & $11.72 \mathrm{e} 5$ & $1.83 \mathrm{e} 6$ & 8.70 & $4.03 \mathrm{e} 6$ \\
\hline & 8 & $23.44 \mathrm{e} 5$ & $3.00 \mathrm{e} 6$ & 5.30 & $3.99 \mathrm{e} 6$ \\
\hline & 10 & $29.30 \mathrm{e} 5$ & $3.59 \mathrm{e} 6$ & 4.44 & $3.93 \mathrm{e} 6$ \\
\hline \multirow{5}{*}{$\begin{array}{l}\text { Restrained block } \\
\text { masonry seismic } \\
\text { wall }\end{array}$} & 2 & $3.68 \mathrm{e} 5$ & $1.03 \mathrm{e} 6$ & 15.52 & 4.03 e 6 \\
\hline & 4 & $7.36 \mathrm{e} 5$ & $1.39 \mathrm{e} 6$ & 11.42 & $4.00 \mathrm{e} 6$ \\
\hline & 8 & $14.72 \mathrm{e} 5$ & 2.13 e 6 & 7.47 & 3.94 e6 \\
\hline & 10 & $18.40 \mathrm{e} 5$ & $2.50 \mathrm{e} 6$ & 6.37 & 3.91 e 6 \\
\hline & 12 & $22.08 \mathrm{e} 5$ & $2.87 \mathrm{e} 6$ & 5.55 & 3.84 e 6 \\
\hline \multirow{5}{*}{$\begin{array}{l}\text { Restrained concrete } \\
\text { seismic wall }\end{array}$} & 2 & $5.06 \mathrm{e} 6$ & 5.72 e 6 & 2.78 & $13.59 \mathrm{e} 6$ \\
\hline & 4 & $10.12 \mathrm{e} 6$ & $10.78 \mathrm{e} 6$ & 1.48 & $13.23 \mathrm{e} 6$ \\
\hline & 6 & $15.18 \mathrm{e} 6$ & $15.84 \mathrm{e} 6$ & 1.01 & $12.87 \mathrm{e} 6$ \\
\hline & 8 & $20.24 \mathrm{e} 6$ & $20.90 \mathrm{e} 6$ & 0.76 & $12.51 \mathrm{e} 6$ \\
\hline & 10 & $25.30 \mathrm{e} 6$ & $25.96 \mathrm{e} 6$ & 0.61 & $11.97 \mathrm{e} 6$ \\
\hline
\end{tabular}

Table 3. Continued.

\begin{tabular}{|c|c|c|c|c|c|}
\hline Wall types & & $\begin{array}{l}\text { seismic shear adjustment } \\
\text { coefficient of the bottom floor }\end{array}$ & $\begin{array}{l}\text { seismic shear coefficient } \\
\text { of one brick masonry wall }\end{array}$ & $\begin{array}{l}\text { seismic shear coefficient of } \\
\text { one reinforced concrete wall }\end{array}$ & $\begin{array}{l}\text { seismic shear coefficient of } \\
\text { one column }\end{array}$ \\
\hline \multirow{5}{*}{$\begin{array}{l}\text { Restrained } \\
\text { brick masonry } \\
\text { seismic wall }\end{array}$} & 2 & 1.250 & 0.051 & 0.261 & 0.0050 \\
\hline & 4 & 1.260 & 0.044 & 0.266 & 0.0051 \\
\hline & 6 & 1.250 & 0.04 & 0.267 & 0.0051 \\
\hline & 8 & 1.260 & 0.039 & 0.274 & 0.0052 \\
\hline & 10 & 1.270 & 0.033 & 0.280 & 0.0053 \\
\hline \multirow{5}{*}{$\begin{array}{l}\text { Restrained } \\
\text { block } \\
\text { masonry } \\
\text { seismic wall }\end{array}$} & 2 & 1.256 & 0.044 & 0.270 & 0.0049 \\
\hline & 4 & 1.259 & 0.040 & 0.274 & 0.0050 \\
\hline & 6 & 1.263 & 0.036 & 0.280 & 0.0051 \\
\hline & 8 & 1.265 & 0.034 & 0.282 & 0.0051 \\
\hline & 10 & 1.269 & 0.030 & 0.287 & 0.0052 \\
\hline
\end{tabular}




\begin{tabular}{|c|c|c|c|c|c|}
\hline Wall types & & $\begin{array}{l}\text { seismic shear adjustment } \\
\text { coefficient of the bottom floor }\end{array}$ & $\begin{array}{l}\text { seismic shear coefficient } \\
\text { of one brick masonry wall }\end{array}$ & $\begin{array}{l}\text { seismic shear coefficient of } \\
\text { one reinforced concrete wall }\end{array}$ & $\begin{array}{l}\text { seismic shear coefficient of } \\
\text { one column }\end{array}$ \\
\hline \multirow{6}{*}{$\begin{array}{l}\text { Restrained } \\
\text { concrete } \\
\text { seismic wall }\end{array}$} & 12 & 1.276 & 0.022 & 0.297 & 0.0054 \\
\hline & 2 & 1.230 & 0.028 & 0.227 & 0.0050 \\
\hline & 4 & 1.240 & 0.029 & 0.226 & 0.0050 \\
\hline & 6 & 1.250 & 0.030 & 0.225 & 0.0052 \\
\hline & 8 & 1.250 & 0.031 & 0.225 & 0.0052 \\
\hline & 10 & 1.270 & 0.033 & 0.224 & 0.0052 \\
\hline
\end{tabular}

According to the calculation in Table 3 :

1) When all concrete anti-seismic walls are selected for the project, when the number of anti-seismic walls is $n=2$, the layer stiffness ratio is $r=2.78$; when $n=4, r=1.48$; when $\mathrm{n}=6, \mathrm{r}=1.01$; when $\mathrm{n}$ is greater than or equal to 8 , $r$ is less than or equal to 1 , which does not meet the requirements. Therefore, the number of seismic walls is not as good as the more, which is limited by the stiffness ratio and layout plan.

2) When restrained brick masonry anti-seismic walls are selected in the project, theoretical calculation shows that when the number of anti-seismic walls $\mathrm{n}$ is greater than or equal to 20 and less than or equal to 52 , the storey stiffness ratio meets the specification requirements, that is, when $\mathrm{n}=20, \mathrm{r}=2.44, \mathrm{n}=52, \mathrm{r}=1.00$; however, according to the plan of the project, so many anti-seismic walls can not be arranged, which is not in line with the actual project, so the project can not adopt all of them restrained brick masonry seismic wall.

3) When restrained block masonry anti-seismic walls are used in the project, when the number of anti-seismic walls $n$ is greater than or equal to 32 , that is, when $n=32, r=2.43$ can meet the requirements of the specification for storey stiffness ratio. According to the anti-seismic design specification, this situation is only applicable to buildings with 6 degree anti-seismic fortification and less than or equal to four floors. According to the plan of the project, all the restrained block masonry cannot meet the requirements.

\section{Selection of Reinforcement Scheme}

In some areas of our country, due to the increase of seismic fortification intensity, some existing masonry structures with bottom frame do not meet the requirements of the current codes. The original structure can be strengthened by changing the wall type and increasing the number of walls, so as to avoid the demolition and reconstruction of the existing structure, resulting in unnecessary waste.

It can be seen from the above calculation that in order to reduce the seismic action bearing by the column, the following two schemes can be adopted, i.e. scheme I, to improve the material strength of seismic wall; scheme II, to increase the number of seismic walls and change the type of seismic wall, i.e. to replace the restrained brick masonry or block masonry wall with reinforced concrete seismic wall. For restrained brick masonry or block masonry wall, scheme I is adopted to improve the material strength with good effect; for concrete seismic wall, scheme II is adopted to increase the number of walls.

\section{Conclusion}

From the above calculation and analysis, we can see that:

1) Through increasing the concrete strength grade of the bottom anti-seismic wall to the stiffness of the bottom layer (the layer stiffness ratio is within a reasonable range), the effect is more obvious than increasing the strength grade of the brick and block; Through increasing the strength grade of the block reduce the seismic shear force distributed to the column, which is better than increasing the strength of the concrete wall; But there are some limitations in reducing the seismic load of the bottom frame column through changing the material strength.

2) The number of anti-seismic walls has a greater impact on the seismic action of the bottom frame columns, and has a smaller impact on the storey stiffness ratio, and there will be certain limitations to improve the bottom stiffness by changing the number of walls. Using reinforced concrete seismic walls instead of restrained brick masonry or block masonry seismic wall can improve the stiffness of the bottom floor and reduce the seismic action of the bottom frame column.

3) When other conditions of the project remain unchanged, in order to ensure that the stiffness ratio between storey meets the reasonable requirements, when reinforced concrete seismic walls are used, the number of walls can be reduced; the number of seismic walls should be controlled within a reasonable range, not the more the better.

\section{Research Fund}

Jiangsu Provincial Department of science and technology projects (2015ZD78).

\section{References}

[1] Zhang Yilei, Li Qingyang, Gao Xiaowang. Analysis of seismic damage mechanism of masonry building with typical bottom frame seismic wall [J], building structure, 2011, 4.

[2] Zhou Wei, Zheng Wenzhong, Tong Jiaying, sing Jiaming. Earthquake damage analysis and earthquake resistant strengthening of buildings in Wenchuan earthquake [J], Journal of Harbin University of technology, 2013. 15: 1-9.

[3] PARKYJ, ANG A H-S, WEN Y K. Seismic damage analysis of reinforced concrete buildings [J]. Journal of Structural Engineering, 1985, 111 (4): 740-757. 
[4] WAEL A Z, HIROSHI M. Residual displacements ofconcrete bridge piers subjected to near field earthquakes $[\mathrm{J}]$. ACI Structural Journal, 2002, 99 (6): 740-749.

[5] KWAN W P, BILLINGTON S. Unbonded posttensioned concrete bridge piers I: monotonic and cyclic analyses $[\mathrm{J}]$. Journal of Bridge Engineering, 2003, 8 (2): 92-101.

[6] Xiong Lihong, Gao Lianjun, et al. Study on seismic performance of bottom frame masonry buildings [J]. Journal of Shenyang University of Architecture (NATURAL SCIENCE EDITION) 2008 (6): 24-4.

[7] $\mathrm{Hu}$ zongchen. Research on seismic behavior of masonry structure with bottom frame seismic wall [D]. Anhui University of architecture, 2014. 3.

[8] Zhu Bingyin. Code for seismic design of buildings applied to analysisGB50011-2010 [M], China Construction Industry Press, 2011.

[9] Song Linbo, Analysis and verification of seismic performance of masonry building with frame shear wall on the bottom two floors [D], Chongqing University, 2011-5.

[10] Wang Wei. Discussion on structural design of masonry building with bottom frame and anti-seismic wall [J]. China Science and Technology Expo, 2009 (26): 3-7.

[11] "Technical code for seismic design of masonry building with bottom frame and seismic wall” (JGJ248-2012) [M], China Construction Industry Press, 2012.
[12] Zhao Jie. Study on the seismic defense line of the whole system of the bottom two story frame seismic of wall masonry building wall column beam stair [D]. Shandong: Shandong University of architecture, 2013.

[13] Zhu Hai. Research on adjustment method of stiffness ratio of bottom frame seismic wall structure [J], Chinese and foreign buildings, 2014, 8: 138-139.

[14] «Code for seismic design of buildings» (GB50011-2010) [M], China Construction Industry Press, 2010.

[15] «Code for design of masonry structure» (GB50003-2011) [M], China Construction Industry Press, 2012.

\section{Biography}

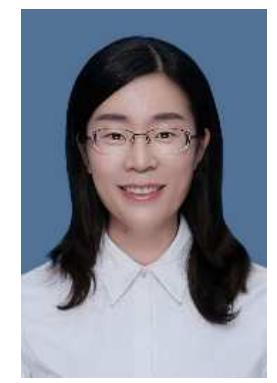

Su Gao (1979.12-), female, Master's degree, research direction: Engineering Mechanics and Building Structure. 